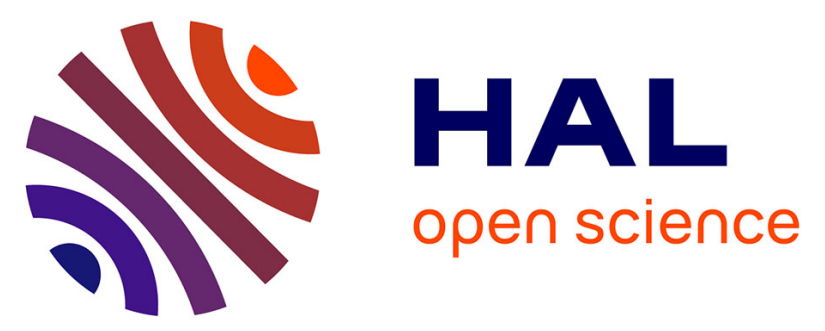

\title{
An Artificial Neuron Network With Parameterization Scheme for Estimating Net Surface Shortwave Radiation From Satellite Data Under Clear Sky-Application to Simulated GF-5 Data Set
}

Menglin Si, Bo-Hui Tang, Zhao-Liang Li, Françoise Nerry, Xia Zhang, Guofei Shang

\section{To cite this version:}

Menglin Si, Bo-Hui Tang, Zhao-Liang Li, Françoise Nerry, Xia Zhang, et al.. An Artificial Neuron Network With Parameterization Scheme for Estimating Net Surface Shortwave Radiation From Satellite Data Under Clear Sky-Application to Simulated GF-5 Data Set. IEEE Transactions on Geoscience and Remote Sensing, 2021, 59 (5), pp.4262-4272. 10.1109/TGRS.2020.3009647 . hal-03005960

\author{
HAL Id: hal-03005960 \\ https://hal.science/hal-03005960
}

Submitted on 1 Dec 2020

HAL is a multi-disciplinary open access archive for the deposit and dissemination of scientific research documents, whether they are published or not. The documents may come from teaching and research institutions in France or abroad, or from public or private research centers.
L'archive ouverte pluridisciplinaire HAL, est destinée au dépôt et à la diffusion de documents scientifiques de niveau recherche, publiés ou non, émanant des établissements d'enseignement et de recherche français ou étrangers, des laboratoires publics ou privés. 


\title{
An Artificial Neuron Network With Parameterization Scheme for Estimating Net Surface Shortwave Radiation From Satellite Data Under Clear Sky-Application to Simulated GF-5 Data Set
}

\author{
Menglin $\mathrm{Si}^{\circledR}$, Student Member, IEEE, Bo-Hui Tang ${ }^{\circledR}$, Senior Member, IEEE, \\ Zhao-Liang Li, Senior Member, IEEE, Françoise Nerry, Xia Zhang, and Guofei Shang
}

\begin{abstract}
Net surface shortwave radiation (NSSR) is a key parameter that drives the surface material exchange and energy balance. Herein, we propose an improved artificial neuron network (ANN) with parameterized (ANN-P) method to first calculate the albedo at the top of atmosphere (TOA) by considering the surface non-Lambertian effect. Subsequently, the NSSR is estimated based on the relationship between TOA broadband albedo and the Earth's surface-absorbed shortwave radiation using a parameterized method under clear sky. The modeling process is implemented with Chinese Gaofen-5 (GF-5) visible/near-infrared channels data simulated via MODTRAN. For comparison, a previously reported lookup table (LUT) with parameterized (LUT-P) method and an ANN method are also employed. The performances of all these methods are evaluated. In terms of model simulation part, the root-mean-square errors (RMSEs) are 15.01 (17.07), 10.04 (13.67), and 20.39 (29.99) $\mathrm{W} / \mathrm{m}^{2}$ for land, water, and snow/ice surfaces, respectively, for the ANN-P (versus LUT-P) method. Their mean bias errors (MBEs) are within $0.9 \mathrm{~W} / \mathrm{m}^{2}$. With respect to the direct ANN method,
\end{abstract}

Manuscript received December 31, 2019; revised May 28, 2020; accepted July 13, 2020. This work was supported in part by the National Natural Science Foundation of China under Grant 41871244, and in part by the Innovation Project of LREIS under Grant O88RA801YA. The work of Menglin Si was supported by the China Scholarship Council for her stay in ICube, France. (Corresponding authors: Bo-Hui Tang; Guofei Shang.)

Menglin Si is with the State Key Laboratory of Resources and Environment Information System, Institute of Geographic Sciences and Natural Resources Research, Chinese Academy of Sciences, Beijing 100101, China, also with the College of Resources and Environment, University of Chinese Academy of Sciences, Beijing 100049, China, and also with ICube Laboratory, UMR 7357, CNRS-University of Strasbourg, 67412 Illkirch, France (e-mail: siml.17b@igsnrr.ac.cn).

Bo-Hui Tang is with the State Key Laboratory of Resources and Environment Information System, Institute of Geographic Sciences and Natural Resources Research, Chinese Academy of Sciences, Beijing 100101, China, also with the College of Resources and Environment, University of Chinese Academy of Sciences, Beijing 100049, China, and also with the Jiangsu Center for Collaborative Innovation in Geographical Information Resource Development and Application, Nanjing 210023, China (e-mail: tangbh@igsnrr.ac.cn).

Zhao-Liang Li is with the State Key Laboratory of Resources and Environment Information System, Institute of Geographic Sciences and Natural Resources Research, Chinese Academy of Sciences, Beijing 100101, China, and also with ICube Laboratory, UMR 7357, CNRS-University of Strasbourg, 67412 Illkirch, France (e-mail: lizhaoliang@caas.cn).

Françoise Nerry is with ICube Laboratory, UMR 7357, CNRS-University of Strasbourg, 67412 Illkirch, France (e-mail: f.nerry@unistra.fr).

Xia Zhang and Guofei Shang are with the College of Land Resources and Urban and Rural Planning, Hebei GEO University, Shijiazhuang 050031, China (e-mail: zhangx396@nenu.edu.cn; shangguofei@hgu.edu.cn).

Color versions of one or more of the figures in this article are available online at http://ieeexplore.iee.org.

Digital Object Identifier 10.1109/TGRS.2020.3009647 it shows the highest accuracy yet relatively large deviation for water surface. Additionally, the sensitivity analysis of water vapor content (WVC) confirms that the ANN-P method is more stable than the LUT-P and ANN methods and is, thereby, recommended for clear-sky NSSR estimation. Finally, the ground validations indicate that the mean RMSEs (MBEs) for the LUT-P, ANN-P, and ANN methods are $49.33(-3.01), 47.55(1.75)$, and 104.24 $(-75.72) \mathrm{W} / \mathrm{m}^{2}$, respectively.

Index Terms-Artificial neuron network (ANN), Chinese Gaofen-5 (GF-5), net surface shortwave radiation (NSSR), top of atmosphere (TOA) broadband albedo.

\section{INTRODUCTION}

$\mathbf{N}$ ET surface shortwave radiation (NSSR) is defined as the difference between the downwelling and upwelling shortwave $(0.3-5 \mu \mathrm{m})$ radiation fluxes on the Earth's surface [1]. It is a key parameter for estimating the surface energy budget, and its quantification over heterogeneous land surfaces is crucial for examining land-atmosphere interactions [2]. Remote sensing can provide land surface attributes with unparalleled spatiotemporal resolution and coverage, and thus a series of studies attempted to estimate NSSR by exploiting remote sensing observations [3]. To date, several surface radiation budget (SRB) products, including the International Satellite Cloud Climatology Project data set (ISCCP-FD) [4], Clouds and the Earth's Radiant Energy System (CERES) Energy Balanced and Filled (EBAF) data [5], [6], and Global Energy and Water Cycle Experiment (GEWEX) SRB [7] data were generated from a number of remote sensing data. Although the products contain radiation components with fine temporal resolutions ( $1-3 \mathrm{~h})$, the spatial resolutions are relatively coarse and range from $\sim 30 \mathrm{~km}$ to $2.5^{\circ}$ [8], [9], thereby hindering relevant land applications like high-resolution (about 1-5 km) forecast systems and mesoscale (about 5-30 km) land surface or environmental models [10], [11]. Therefore, it is important to develop new methods for retrieving NSSR with finer spatiotemporal resolution and high accuracy based on satellite remote sensing technology.

Over the past decades, considerable methods are proposed to estimate NSSR from satellite-derived radiative data at the top of atmosphere (TOA) or along with ancillary land and atmospheric information. The majority of the methods 
are categorized into parametric methods, empirical methods, physical methods, and hybrid methods.

1) Parametric methods typically calculate NSSR by parameterized formulae involving atmospheric variables, such as water vapor content WVC) and aerosol extinction. Key meteorological parameters are adopted from satellite remotely sensed data [12], [13], wherein existing uncertainties propagate error in the subsequent process.

2) Empirical methods generally establish simple empirical relationships between satellite level radiance and NSSR. The methods are site- and/or data-specific and are not easily applied to other regions [14].

3) Physics-based methods exhibit optimal accuracy. However, computational complexity limits its application [15].

4) Hybrid methods typically incorporate a large amount of radiative transfer simulations and then implement statistical regression or artificial neuron network (ANN) model based on the simulated database [16]-[21].

Hybrid methods maintain intact physical fundamentals and avoid a complex intermediate process and correspond to the relatively most popular methodology. The majority of the aforementioned methods assume the surface as homogeneous and completely ignore the topographic effects. Several algorithms are developed by combining satellite data and digital elevation model (DEM) to correct pivotal shortwave components on unobstructed surfaces [22]-[28]. However, calculation of a large amount of complicated terrain factors is time-consuming and thus impractical. The requisite DEM product typically corresponds to poor quality.

Currently, a novel perspective is presented to estimate the global radiation budget by considering the atmosphere-Earth surface as a whole system. Given the development of satellite remote sensing, it is possible to directly measure the albedo of the system and subsequently the reflected flux at TOA is easily obtained [29]. Then, based on the parameterized relationship of the TOA broadband albedo or flux and the SRB, the NSSR can be deduced [17], [30]. Several algorithms have been developed to measure the TOA radiation budget [31], [32]. Nevertheless, typically, the preliminary step of these algorithms directly converts narrowband reflectances to broadband albedo via a simple regression operation [33]. Although the models can be constructed for different solarview geometry, the anisotropy of land surface is not fully considered. Given the non-Lambertian characteristic of natural surface and the whole Earth-atmosphere system, an angle directional model is proposed to obtain a better estimate of TOA broadband albedo [34]-[38]. Algorithms are developed based on large amount of radiative transfer calculations for different classifications of surface, atmosphere, and geometrical conditions. Finally, a lookup table (LUT) is constructed in detail at discrete angle bins to describe the relationship between TOA directional reflectance and broadband albedo. The method is relatively complicated and relies on specific satellite product. The emerging ANN method has also been proven feasible in terms of estimating the TOA broadband albedo [39]. Additionally, most of the current schemes to estimate NSSR are appropriate for relatively coarse-resolution satellite-based data such as TOA radiance and atmospheric water vapor products from the Moderate Resolution Imaging Spectroradiometer (MODIS) that exhibit certain uncertainties. Thus, the NSSR estimation results are too rough to feature heterogeneous surface characterization [40]. In summary, it poses an urgent requirement to estimate shortwave radiation budget when applied to nonuniform natural surfaces with finer resolution.

The Chinese Gaofen-5 (GF-5) is a polar-orbiting satellite of a series of China High-Resolution Earth Observation System (CHEOS) satellites of the China National Space Administration launched in 2018 [41], and has been recently proven to be practical in terms of retrieving key surface parameters [42]. It is configured with six payloads, in which the multiple spectral imager (MSI) is designed to collect land information at high spatial resolution for disaster monitoring. The MSI provides 13 channels that cover the spectral range from visible/near-infrared (VIS/NIR) (20-m spatial resolution) to thermal infrared (40-m spatial resolution) [43], from which the first six VIS/NIR channels covering the range corresponding to $0.45-2.35 \mu \mathrm{m}$ exhibit a potential to estimate NSSR at 20$\mathrm{m}$ spatial resolution. Therefore, the objective of this study is to develop an improved hybrid method by considering the non-Lambertian characteristics of the natural surface to first obtain TOA broadband albedo and then estimate NSSR with GF-5 data under clear sky. This study is limited to cloudless days because the cloudy-sky situation is complicated, and in majority of cases, the sky is sparsely or partially cloudy. The cloud optical properties or microphysical characteristics are difficult to measure accurately, especially when the liquid water exists. Furthermore, the radiative transfer simulation model (e.g., MODTRAN) can only offer fully cloudy data set with a limited variety of cloud types. Hence, only the clear sky condition is selected in this study.

The remainder of this article is organized as follows. Section II describes the basic materials required and then the proposed integrated method is presented. The results of estimation and validation against satellite and ground measurements are detailed in Sections III and IV. In Section V, necessary discussion is stated and relevant main conclusions are listed.

\section{Materials And Methods}

\section{A. Bidirectional Reflectance Distribution Function Parameters}

MODIS onboard the NASA Terra and Aqua satellites provides an opportunity to retrieve the operational bidirectional reflectance distribution function (BRDF) and albedo products [44]. The algorithm uses a kernel-driven BRDF model that is linear in its parameters and relies on the weighted sum of an isotropic parameter and two kernels of viewing and illumination geometry to determine reflectance [45], as expressed in the following equation:

$$
\begin{aligned}
R\left(\theta_{\mathrm{s}}, v, \varphi, \lambda\right)=f_{\mathrm{iso}}(\lambda)+f_{\mathrm{vol}}(\lambda) & K_{\mathrm{vol}}\left(\theta_{\mathrm{s}}, v, \varphi, \lambda\right) \\
+ & f_{\mathrm{geo}}(\lambda) K_{\mathrm{geo}}\left(\theta_{\mathrm{s}}, v, \varphi, \lambda\right)
\end{aligned}
$$


where $\theta_{\mathrm{s}}, v$, and $\varphi$ denote the solar zenith angle (SZA), view zenith angle (VZA), and relative azimuth angle (RAA), respectively. Specifically, $f_{\text {iso }}(\lambda)$ denotes the Lambertian scattering component and is equal to the bidirectional reflectance for $\theta_{\mathrm{s}}=0^{\circ}$ and $v=0^{\circ}$. Furthermore $f_{\text {iso }}(\lambda)$ denotes the coefficient for the Ross thick volume scattering kernel $K_{\mathrm{vol}}\left(\theta_{\mathrm{s}}, v, \varphi, \lambda\right)$ derived from volume scattering radiative transfer models. $f_{\text {geo }}(\lambda)$ denotes the coefficient of the $\mathrm{Li}$ sparse-reciprocal geometric scattering kernel $K_{\text {geo }}\left(\theta_{\mathrm{s}}, v, \varphi, \lambda\right)$ from surface scattering and geometric shadow casting theory. The kernel combination model is observed to perform well with reliable and consistent surface reflectances over a wide range of surface covers. The global BRDF/Albedo model parameters Daily product MCD43A1 in 2018 is employed. It provides the three parameters in Ross-Li BRDF model for MODIS bands $1-7(0.62-2.15 \mu \mathrm{m})$ as well as for three broad bands $(0.3-0.7,0.7-5.0$, and $0.3-5.0 \mu \mathrm{m})$. It is currently one of the best products that provide comprehensive BRDF parameters within the shortwave radiation spectral range for Ross-Li model, which is consistent with that embedded in MODTRAN, to calculate the surface directional reflectances. Given the seasonal variation of land surface features, the BRDF parameters of each land type will also change within the year. The products over all year are averaged as final BRDF parameters. Additionally, the MODIS land cover product MCD12 in 2018 (https://ladsweb.modaps.eosdis.nasa.gov/) is selected as a mask to extract the BRDF parameters for each land type.

\section{B. Training Database Preparation}

Key variables, such as TOA broadband albedo and shortwave fluxes at TOA and surface, are retrieved by running an atmospheric radiative transfer model (MODTRAN 5.2) to construct the database at first. Seven surface types depicting representative reflectance spectral are employed based on the International Geosphere-Biosphere Programme (IGBP) land type classification [46], including barren or sparsely vegetated, evergreen broadleaf forest, grassland, cropland, permanent wetland, water, and snow and ice. The directional reflectance is calculated by the MODTRAN internal "Ross-Li" BRDF model consistent with the MODIS BRDF algorithm. Under six MODTRAN standard atmospheric profiles (i.e., tropical atmosphere, middle latitude summer atmosphere, mid latitude winter atmosphere, subarctic summer atmosphere, subarctic winter atmosphere, and United States 1976 standard atmosphere), the WVCs correspond to 0.42 , $0.85,1.42,2.08,2.92,4.11,5.76$, and $6.58 \mathrm{~g} / \mathrm{cm}^{2}$, respectively. Two aerosol extinction types (rural, maritime) with six different visibilities (VISs) $(5,10,15,23,50$, and $150 \mathrm{~km})$ are also considered. Furthermore, based on different view geometry, seven RAAs $\left(0^{\circ}-180^{\circ}\right.$ at an interval of $\left.30^{\circ}\right)$ and seven SZAs $\left(0^{\circ}, 10^{\circ}, 20^{\circ}, 40^{\circ}, 50^{\circ}, 60^{\circ}, 70^{\circ}\right)$ are deployed. Considering the MSI onboard GF-5 observes the Earth almost at nadir, the VZA is set to $0^{\circ}$. Finally, 37044 cases are prepared for the MODTRAN simulation code. The GF-5 channel radiance is then obtained with the simulated database based on its spectral response function. The responses of its first six bands are shown in Fig. 1.

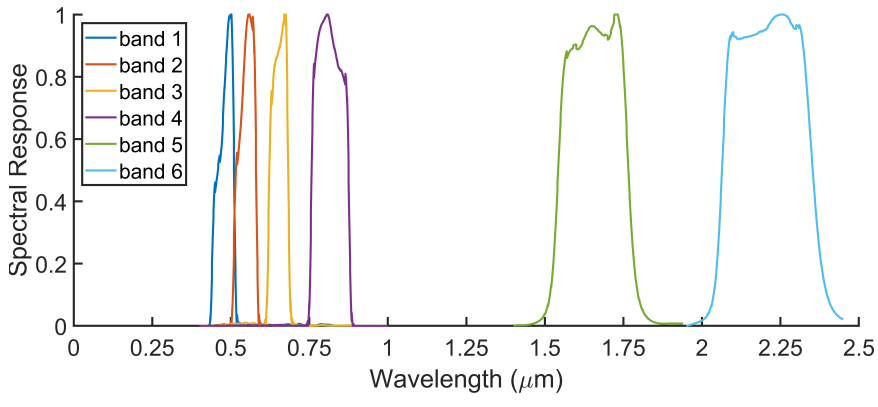

Fig. 1. Spectral response curves of first six bands for GF-5.

\section{TOA Broadband Albedo Estimation}

To improve the accuracy in TOA broadband albedo estimation, a genetic algorithm (GA)-based back propagation (BP) neural network (GA-BP) is employed. In machine learning and cognitive science domain, ANN correspond to a family of statistical learning models inspired by biological neural networks. Specifically, ANN is a robust empirical statistical method to estimate or approximate functions that depend on a large number of inputs and are generally unknown, and it is applied in a variety of applications including classification, pattern recognition, forecasting, signal processing, and geosciences [47]. The BP neural network is a multilayer feedforward network trained based on error BP algorithm (which is a common method of teaching artificial neural networks on how to perform a given task) and is one of the most widely applied neural network models. The GA is a method inspired by the process of natural selection and biological evolution for solving both constrained and unconstrained optimization problems, and thus, is generally imported to determine the initial weight (which is a sensitive factor to affect the performance of an ANN model). Additionally, the number of nodes $(N)$ in the hidden layer can also evidently affect simulation accuracy. An ANN model with an excessive number of neurons frequently leads to overfitting while an insufficient number of neurons typically leads to underfitting or low correlation. Two ANN schemes with and without visibility as input parameter are executed separately and yield similar model performances. It indicates that the influence of aerosol on TOA broadband albedo in the ANN model could be ignored. To keep the model conciseness and reduce the uncertainty caused by superfluous parameters, the VIS is not considered and TOA channel reflectances, WVC, RAA, and SZA are set as inputs and TOA broadband albedo as output to execute the ANN model. Finally, the GA-BP simulations are iteratively conducted by only changing the $\mathrm{N}$ in the hidden layer from 1 to 100 and the optimal ANN network with the least root-mean-square error (RMSE) is determined.

The TOA shortwave narrowband reflectance at certain direction $\rho_{i}\left(\mu_{\mathrm{s}}, \mu_{\mathrm{v}}, \varphi\right)$ is calculated from TOA radiance for each band, respectively,

$$
\rho_{i}\left(\mu_{\mathrm{s}}, \mu_{\mathrm{v}}, \varphi\right)=\frac{\pi L_{i}\left(\mu_{\mathrm{s}}, \mu_{\mathrm{v}}, \varphi\right) d^{2}}{\mu_{\mathrm{s}} \bar{E}_{\text {band } \_i}}
$$

where $\mu_{\mathrm{s}}$ denotes the cosine of SZA, $\mu_{\mathrm{v}}$ denotes the cosine of VZA, and $\varphi$ denotes RAA. Additionally, $L_{i}\left(\mu_{\mathrm{s}}, \mu_{\mathrm{v}}, \varphi\right)$ denotes the TOA radiance corresponding to the reflection direction at 
band $i, d$ denotes the Earth-Sun distance in astronomical units, and $\bar{E}_{\text {band } \_i}$ denotes the mean exoatmospheric irradiance at band $i$, which could be derived from MODTRAN simulation results. Finally, The TOA shortwave broadband albedo $r$ is calculated as follows:

$$
r=\frac{F_{\mathrm{u}} d^{2}}{E_{0} \mu_{\mathrm{s}}}
$$

in which $F_{\mathrm{u}}$ denotes the TOA shortwave upward flux $\left(\mathrm{W} / \mathrm{m}^{2}\right)$, and $E_{0}$ denotes the TOA solar irradiance at one astronomical unit $\left(\mathrm{W} / \mathrm{m}^{2}\right)$.

For comparison purposes, the linear conversion from narrowband reflectance to broadband albedo at TOA is also implemented. A new LUT is reconstructed. The detailed operation is based on Tang et al. [17]. Based on the new LUT, the TOA broadband albedo is estimated. The cases whose SZAs and RAAs are absent in the LUT are linearly interpolated from those derived from the neighboring angle bins.

\section{NSSR Estimation}

Li and Leighton [30] proposed a linear model to describe the relationship between the TOA upward shortwave flux and NSSR based on radiative transfer calculation where the SZA and water vapor amount correspond to the only input parameters. As noted by Masuda et al. [13], the flux absorbed at the surface is related to the normalized TOA upward shortwave flux. The surface absorption coefficient $a_{\mathrm{s}}$ is defined as a fraction of the flux incident. By exploiting the MODTRAN simulated data, $a_{\mathrm{s}}$ is retrieved based on the following linear relationship with TOA broadband albedo $r$ as follows:

$$
a_{\mathrm{s}}\left(\mu_{\mathrm{s}}, w, r\right)=\alpha^{\prime}-\beta^{\prime} r
$$

where $a_{\mathrm{s}}$ is defined based on the following formula:

$$
a_{\mathrm{s}}=\frac{\mathrm{NSSR} d^{2}}{E_{0} \mu_{\mathrm{s}}} .
$$

The intercept term $\alpha^{\prime}$ and slope coefficient $\beta^{\prime}$ are expressed as follows:

$\alpha^{\prime}=1-a_{1} \mu_{\mathrm{s}}^{-1}-a_{2} \mu_{\mathrm{s}}^{-x}-\left(1-\exp \left(-\mu_{\mathrm{s}}\right)\right)\left(a_{3}+a_{4} w^{y}\right) \mu_{\mathrm{s}}^{-1}$

and

$$
\beta^{\prime}=\left(1+a_{5}+a_{6} \ln \mu_{\mathrm{s}}+a_{7} w^{z}\right)
$$

where $w$ denotes the atmospheric precipitable water vertical content $\left(\mathrm{g} / \mathrm{cm}^{2}\right)$. For different surface types, $a_{1}-a_{7}$ and $x, y, z$ denote various constants.

To obtain the ten coefficients in (6) and (7), the MODTRAN simulated data in Section II-B is first categorized into three types, namely land, water, and snow and ice surfaces, and then employed to separately determine the parameters. The dependent $a_{\mathrm{s}}$ is calculated using (4). The independent $r$ is the TOA broadband albedo simulated by MODTRAN. Finally, coefficients for land surface are retrieved based on 26460 pairs of $a_{\mathrm{s}}$ and $r$. Similarly, 5292 sets of samples are separately generated for the water and snow and ice surfaces.

Tang et al. [17] primitively developed a direct method and reparameterized Li's model to estimate NSSR by using MODIS TOA narrowband radiance and reflectance data, which

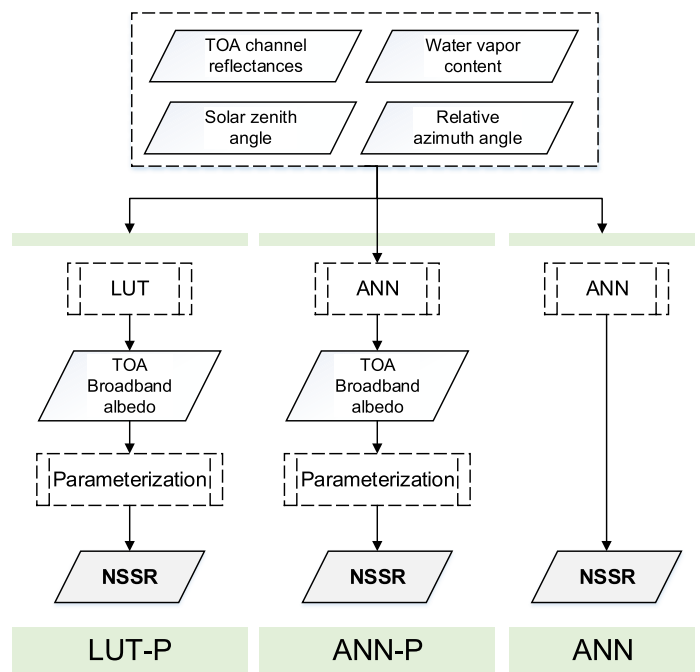

Fig. 2. Workflow of the LUT-P, ANN-P, and ANN methods for NSSR estimation.

is also introduced in this section for continuity. In this section, variable $r$ is also from the MODTRAN simulation. The parameterized coefficients are recalculated based on the GF-5 simulation database.

Finally, the ANN method is also directly employed to estimate NSSR based on satellite radiance data, atmospheric parameters, and geometry conditions for further comparison with the proposed ANN with parameterization (ANN-P) method. An optimization scheme for GA-based initial weight and selection of best $N$ in hidden layers is also exerted in a manner similar to the TOA broadband albedo estimation in Section II-C. In this study, we take the atmosphere-Earth surface as a whole system and the difference between the incident solar energy and the satellite captured energy is the total absorption through the system, which includes the atmosphere absorption and surface absorption. The NSSR is the surface absorbed energy, which could be retrieved by removing the atmosphere absorption from the total absorption of this system. The atmosphere absorbs solar energy through atmospheric molecules (e.g., water vapor), aerosol, and cloud. The cloud was not considered in this study. The absorption effect of atmospheric aerosol on shortwave radiation is negligible. Therefore, the absorption through the atmosphere was characterized specifically by the variable WVC. To retain the model conciseness and reduce the uncertainty caused by superfluous parameters, the VIS is not considered and TOA channel reflectances, WVC, RAA, and SZA are set as inputs and NSSR as output to execute the ANN model. An ANN training is executed by putting all data set together while the accuracy is observed as worse than when different land types are operated separately. Specifically, all three types of land surfaces are separately operated. The workflow of the LUT with parameterization (LUT-P) method, ANN-P, and ANN method for NSSR estimation is presented in Fig. 2.

\section{E. Ground Validation With GF-5 Satellite Proxy Data}

Currently, the Chinese GF-5 satellite data are unavailable. To implement the validation, the Landsat 8 Operational Land Imager (OLI) is employed as proxy of GF-5/MSI. As shown 
TABLE I

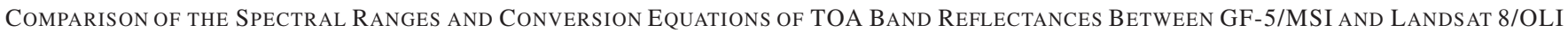

\begin{tabular}{cccc}
\hline \hline & $\begin{array}{c}\text { GF-5 Multiple Spectral Imager } \\
(\mathrm{MSI})\end{array}$ & $\begin{array}{c}\text { Landsat-8 Operational Land Imager } \\
(\mathrm{OLI})\end{array}$ & Conversion equation \\
\hline & $\mathrm{B} 1: 0.45-0.52 \mu \mathrm{m}$ & $\mathrm{B} 1: 0.433-0.453 \mu \mathrm{m}$ & \\
& $\mathrm{B} 2: 0.450-0.515 \mu \mathrm{m}$ & $\rho_{M S I}=0.996 \rho_{\text {OLI }}+0.003$ \\
Spectral range/ & $\mathrm{B} 3: 0.62-0.68 \mu \mathrm{m}$ & $\mathrm{B} 3: 0.525-0.600 \mu \mathrm{m}$ & $\rho_{\text {MSI }}=1.015 \rho_{\text {OLI }}+0.002$ \\
conversion equation & $\mathrm{B} 4: 0.76-0.86 \mu \mathrm{m}$ & $\mathrm{B} 4: 0.630-0.680 \mu \mathrm{m}$ & $\rho_{M S I}=0.995 \rho_{\text {OLI }}+0.001$ \\
& $\mathrm{~B} 5: 1.55-1.75 \mu \mathrm{m}$ & $\mathrm{B} 5: 0.845-0.885 \mu \mathrm{m}$ & $\rho_{\text {MSI }}=0.908 \rho_{\text {OLI }}-0.026$ \\
& $\mathrm{~B} 6: 2.08-2.35 \mu \mathrm{m}$ & $\mathrm{B} 6: 1.56-1.66 \mu \mathrm{m}$ & $\rho_{\text {MSI }}=0.934 \rho_{\text {OLI }}-0.004$ \\
\hline \hline
\end{tabular}

in Table I, the spectral ranges of the corresponding OLI's band 2-band 7 are similar to those in MSI's band 1-band 6, which are selected as the alternative data. To compensate for the difference between the spectral response functions in MSI and OLI, a linear relationship is constructed between the TOA channel reflectances of MSI and OLI based on the MODTRAN simulation data set. The conversion equations from MSI to OLI band reflectances are listed in Table I. Finally, the Landsat 8 OLI data set is collected from June 1, 2018 to December 31, 2019 (https://earthexplorer.usgs.gov/).

Seven stations (i.e., Bondville, IL, USA; Boulder, CO, USA; Desert Rock, NV, USA; Fort Peck, MT, USA; Goodwin Creek, MS, USA; Penn State, PA, USA; and Sioux Falls, SD, USA) in the SURFRAD (SRB) Network (https://www.esrl.noaa.gov/gmd/grad/surfrad/index.html) are selected as optional ground validation sites from June 1, 2018, to December 31, 2019. The spatial heterogeneity of NSSRs at each site were analyzed to pick out the proper ones. The field measurements of NSSR on clear days are selected synchronously with Landsat 8 overpass time. With respect to the meteorological information, the MODIS daily product MOD05_L2 (https://ladsweb.modaps.eosdis.nasa.gov/) is used to retrieve WVC.

\section{RESULTS}

\section{A. Performance of TOA Shortwave Broadband Albedos}

First, the LUT method is employed with similar configuration in Tang et al.'s [17] method and validated via the GF-5 simulation database. As in Fig. 3(a), the estimations with the previous LUT method exhibit a larger deviation from the actual values. Subsequently, the GA-BP is executed and the $N \mathrm{~s}$ in the hidden layer with least RMSEs are 81, 96, and 54 for land, water, and snow and ice surfaces, respectively. The GA-BP networks with least RMSEs are selected for the TOA broadband albedo estimation. Fig. 3(b) shows a comparison of these actual TOA shortwave broadband albedos simulated by MODTRAN and those estimated by GA-BP. The ANN model explains more than $99 \%$ of the TOA broadband albedo variations in the simulated data sets. The results are good with the RMSE less than $0.005 \mathrm{~W} / \mathrm{m}^{2}$ and all sample points are near the 1:1 line except for a few deviations, thereby indicating a well fit of the TOA broadband albedo and providing a satisfactory database for the following NSSR
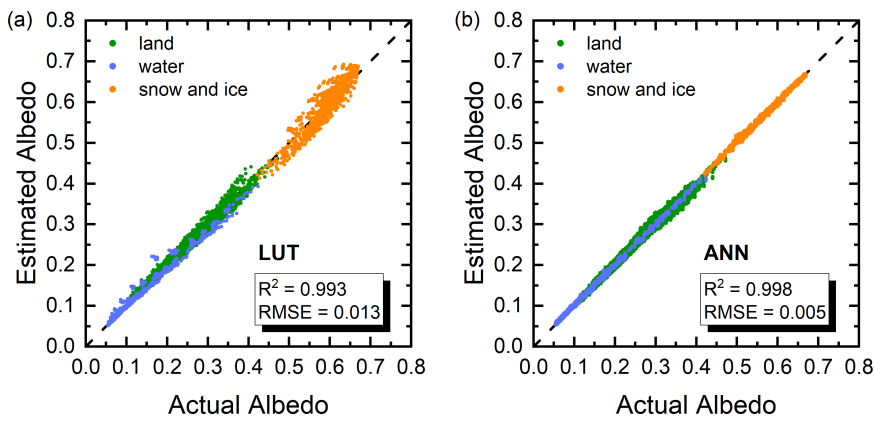

Fig. 3. Comparison of the actual and estimated TOA shortwave broadband albedos under clear sky using (a) LUT method and (b) ANN method described in Section II-C.

estimation. The comparison of their performances indicates that the improved GA-BP method is more suitable for the non-Lambertian database, which is closer to the real natural underlying surface features. The proposed GA-BP method could obtain TOA broadband albedo with increased accuracy, which is crucial for the NSSR estimation.

\section{B. Performance of NSSR Estimation}

The surface absorption coefficient is estimated with (4) wherein parameters are calibrated with the training database in Section II-B. Finally, the NSSR is calculated with (5) and then compared with the simulated (directly obtained from the MODTRAN 5.2) outputs. The coefficients for estimating the NSSR with (4)-(6) are listed in Table II. Three indices are selected to characterize the accuracy of NSSR retrieval, namely coefficient of determination $\left(R^{2}\right)$, mean bias error (MBE), and RMSE. Fig. 4 shows a comparison of actual and estimated NSSR under three different types of surfaces. The upper figures show the evaluation results of previous LUT-P method and lower figures denote the proposed ANN$P$ method. The RMSE values of land, water, and snow and ice surfaces are around $13-30 \mathrm{~W} / \mathrm{m}^{2}$ for the LUT-P method and $10-20 \mathrm{~W} / \mathrm{m}^{2}$ for the improved ANN-P method. In the first row for LUT-P method, a majority of the scatter points are near the 1:1 line and slight underestimation is observed for land surface. The scatter point for water surface is segmentally deviated which could be due to the discontinuity in the TOA broadband albedo estimation based on LUT method. For the snow and ice surface, a few points are deflected irregularly. With respect to the second row for ANN-P method, the result 
TABLE II

CoEfFicients For ESTIMATING THE NSSR With (4)-(6)

\begin{tabular}{ccccccccccccc}
\hline \hline & $\mathrm{a}_{1}$ & $\mathrm{a}_{2}$ & $\mathrm{a}_{3}$ & $\mathrm{a}_{4}$ & $\mathrm{a}_{5}$ & $\mathrm{a}_{5}$ & $\mathrm{a}_{5}$ & $\mathrm{x}$ & $\mathrm{y}$ & $\mathrm{z}$ \\
\hline land & -0.026 & -0.225 & -0.503 & 0.371 & -0.841 & -0.123 & 1.008 & 0.392 & 0.115 & -0.025 \\
water & 0.005 & 0.201 & -0.692 & 0.834 & -0.666 & 0.098 & 0.481 & 0.354 & 0.113 & -0.165 \\
Snow and ice & -0.002 & 0.125 & -0.524 & 0.459 & -0.619 & 0.258 & 1.230 & 0.504 & 0.129 & -0.064 \\
\hline \hline
\end{tabular}
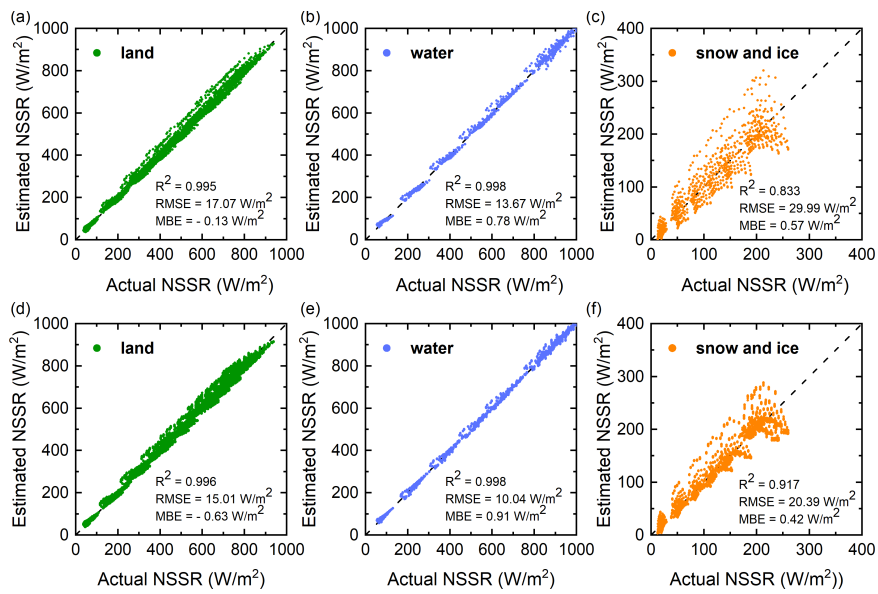

Fig. 4. Comparison of the actual and estimated NSSRs. LUT-P method for (a) land, (b) water, and (c) snow and ice. ANN-P method for (d) land, (e) water, and (f) snow and ice.

for land and water surfaces are also fitted well and show some improvement. For the snow and ice situation, the RMSE is not equally ideal as that in land and water surfaces while anyhow improves a little bit. Generally, snow and ice surfaces have high reflectance and are prone to adjacent terrain reflected radiation. The relatively large RMSE for snow and ice cases is probably due to the global minimization error in (6). In summary, the ANN-P method exhibits better accuracy for each type of surface.

It should be noted that the result presented is based on a calibration process with (4), (6), and (7) with the TOA broadband albedo simulated by MODTRAN. Thus, the errors in the NSSR model fitting process do not include errors in the albedo estimation. In order to test the sensitivity of TOA broadband albedo $(r)$, we also calibrate the parameters in NSSR estimation model with the estimated $r$ and obtain the NSSR, which exhibits comparable accuracy and similar error distribution when compared to that of the result that ignores error propagation. This further indicates adequate accuracy of the TOA broadband albedo estimation.

\section{ANN Method Estimated NSSR}

The ANN method is employed to directly estimate NSSR with the same samples that are used in Sections III-A and IIIB. The training and testing data set are randomly divided by rates corresponding to $80 \%$ and $20 \%$. Based on the simulation result, the RMSEs of different cases with incremental $N$ in the hidden layer are compared as in Fig. 5. At length, 27, 26, and 81 neurons in the hidden layer for land, water, and snow and ice surfaces are selected. The validation process is performed

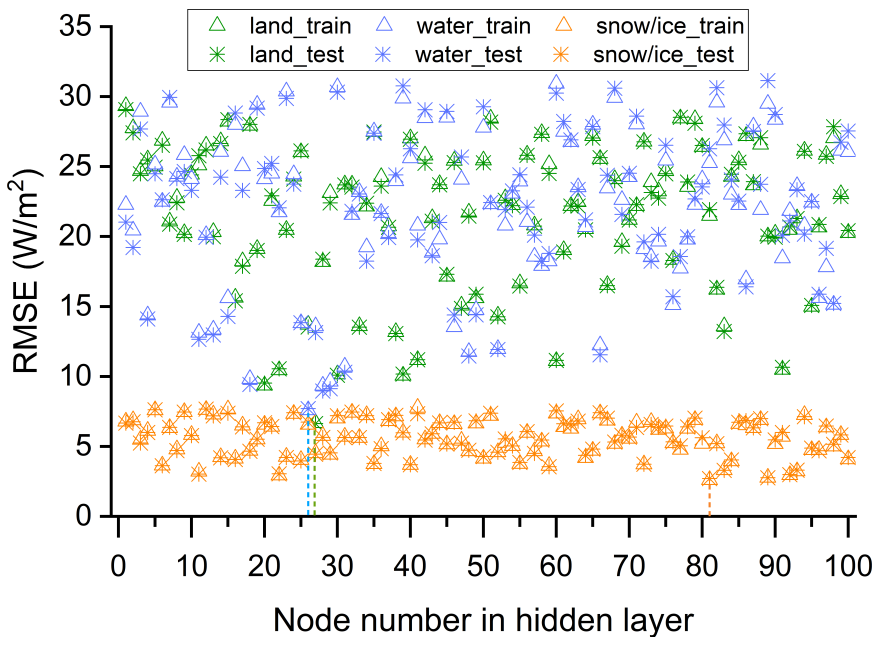

Fig. 5. Comparison of the RMSEs for different ANN schemes with incremental number of nodes in hidden layer. The three vertical dashed lines denote the points with lowest RMSEs.
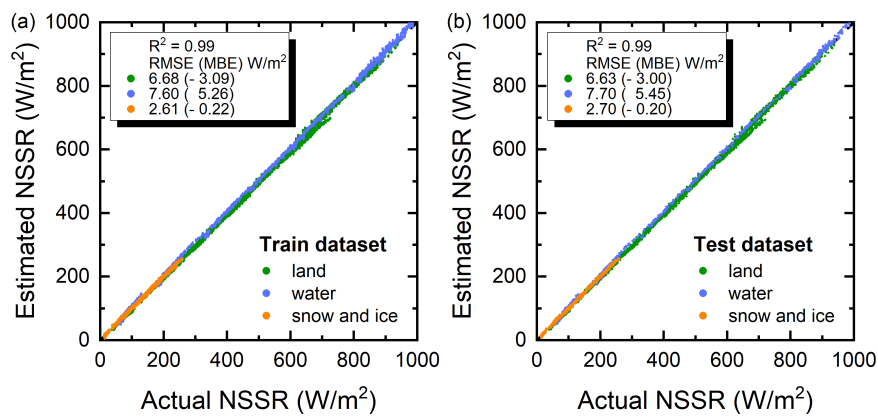

Fig. 6. Comparison of the actual NSSR and estimated NSSR based on ANN method for (a) training data set and (b) testing data set.

to evaluate the ANN method. Fig. 6 shows comparisons between the simulated and estimated NSSR with direct ANN method for training and testing data set. Sufficient agreement is observed between the ANN model fitting and radiative transfer model computations of NSSR, and most scatter points center at the 1:1 line for all three land types. Overall, accuracy is similar in these two parts of the data set, and the ANN model explains more than $99 \%$ of the NSSR variations in all. The RMSEs of land, water, and snow and ice surface are around 2-7 W/m in the testing part. An inconspicuous overestimation exists for water surface with $\mathrm{MBE}$ equals $5.45 \mathrm{~W} / \mathrm{m}^{2}$. With respect to land and snow and ice surface, slight underestimation occurs with MBEs corresponding to -3 and $-0.2 \mathrm{~W} / \mathrm{m}^{2}$, respectively.

When compared to the result in Fig. 4, the ANN method derived NSSR is with prominent higher accuracy for all land types. With respect to the land and water surfaces, the ANN 
TABLE III

COMPARISON OF PERFORMANCES FOR DIFFERENT NSSR ESTIMATION METHODS

\begin{tabular}{ccccc}
\hline \hline & Land type & LUT-P & ANN-P & ANN \\
\hline & land & 17.07 & 15.01 & 6.63 \\
RMSE & water & 13.67 & 10.04 & 7.70 \\
$\left(\mathrm{~W} / \mathrm{m}^{2}\right)$ & Snow and ice & 29.99 & 20.39 & 2.70 \\
\hline & land & -0.13 & -0.63 & -3.00 \\
$\mathrm{MBE}$ & water & 0.78 & 0.91 & 5.45 \\
$\left(\mathrm{~W} / \mathrm{m}^{2}\right)$ & Snow and ice & 0.57 & 0.42 & -0.20 \\
\hline \hline
\end{tabular}

method exhibits relatively better accuracy with RMSEs corresponding to 6.63 and $7.70 \mathrm{~W} / \mathrm{m}^{2}$, respectively, and they are evidently lower than 15.01 and $10.04 \mathrm{~W} / \mathrm{m}^{2}$, respectively, as obtained in ANN-P scheme. Specifically, the RMSEs for snow and ice surface correspond to 2.70 and $20.39 \mathrm{~W} / \mathrm{m}^{2}$, respectively, in the two methods. It is inevitable that in the ANN-P method, the error in the first step of TOA broadband albedo estimation could be transferred into step 2. While in the ANN method, it only contains a direct global optimization process. The improvement of RMSE in the ANN method is probably due to less error propagation in the direct ANN simulation process. With respect to the MBE, in the proposed ANN-P method, the biases for all three surfaces are relatively negligible and more focused on the central line except for the snow and ice surface. While in the ANN method, a significant overestimation is observed for the water surface. The overestimation in the ANN method could be ascribed to the instability of neural network, which will be analyzed in Section III-D. A comparison of the performance of the aforementioned three methods is listed in Table III.

In summary, the proposed ANN-P method significantly improves the accuracy of NSSR estimation when compared to the previous LUT-P method. The ANN method reveals the superior capability of NSSR estimation, especially for the snow and ice surface. However, it is too early to draw a conclusion as to which performance is better and merely based on the simulation data set. The sensitivity of different methods should be further explored as discussed in Section III-D.

\section{Sensitivity Analysis of WVC}

Based on several extant studies, it is not difficult to conclude that the water vapor in the atmosphere is essential parameter that perturbs the surface shortwave radiation budget. To further compare the performance of the LUT-P, ANN-P, and ANN methods, the sensitivity of WVC which reflects the condition of atmosphere is analyzed. By introducing relative WVC errors of $-10 \%,-5 \%, 0 \%,+5 \%$, and $+10 \%$, the RMSEs in different land surface types for three methods are calculated and listed in Table IV.

Fig. 7 shows the difference between the $\mathrm{RMSE}_{i}$ after introducing WVC errors from $-10 \%$ to $+10 \%$ and the RMSE without WVC error for three methods. According to the
TABLE IV

COMPARISON OF RMSES $\left(\mathrm{W} / \mathrm{m}^{2}\right)$ IN DIFFERENT LAND TYPES AFTER INTRODUCING WVC ERRORS FOR DIFFERENT METHODS

\begin{tabular}{ccccccc}
\hline \hline \multirow{2}{*}{ Method } & Surface type & \multicolumn{5}{c}{ Relative WVC errors (\%) } \\
\cline { 3 - 7 } & & -10 & -5 & 0 & +5 & +10 \\
\hline \multirow{3}{*}{ LUT-P } & land & 17.39 & 17.16 & 17.08 & 17.14 & 17.32 \\
& water & 14.39 & 13.92 & 13.67 & 13.61 & 13.73 \\
& Snow and ice & 30.64 & 30.28 & 29.99 & 29.79 & 29.65 \\
\hline \multirow{3}{*}{ ANN-P } & land & 15.29 & 15.08 & 15.01 & 15.07 & 15.22 \\
& water & 10.97 & 10.39 & 10.04 & 9.91 & 9.98 \\
& Snow and ice & 20.99 & 20.67 & 20.39 & 20.16 & 19.96 \\
\hline \multirow{3}{*}{ ANN } & land & 6.54 & 6.52 & 6.67 & 6.98 & 7.42 \\
& water & 9.60 & 8.55 & 7.62 & 6.85 & 6.27 \\
& Snow and ice & 2.50 & 2.53 & 2.63 & 2.85 & 3.21 \\
\hline
\end{tabular}

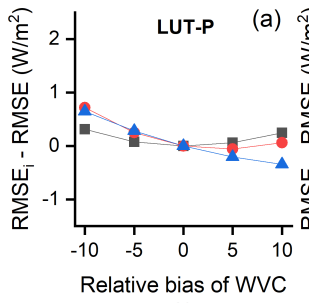

(\%)

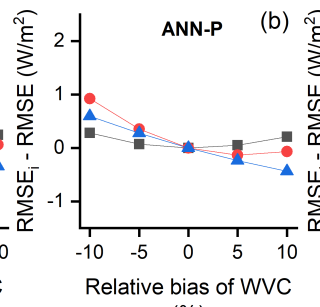

$(\%)$

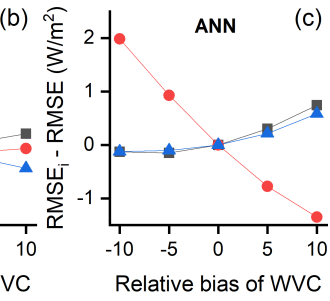

$(\%)$
Fig. 7. Difference between $\mathrm{RMSE}_{i}$ (after introducing WVC errors) and RMSE (without WVC error) for (a) LUT-P, (b) ANN-P, and (c) ANN methods.

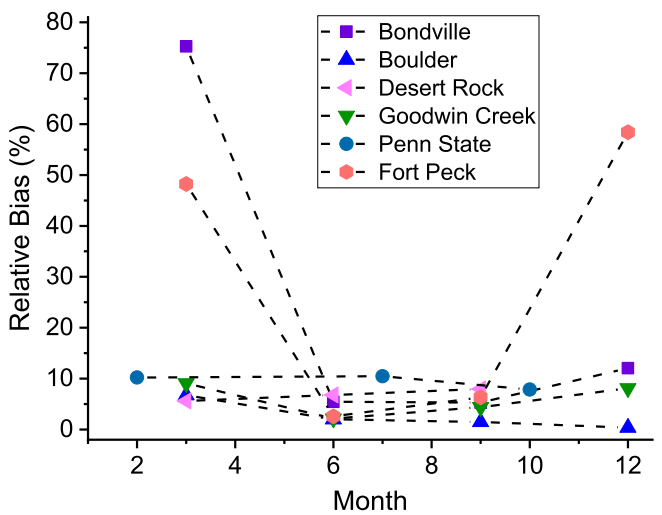

Fig. 8. RB between the in situ measurement at each site and the mean NSSR around neighboring $5 \mathrm{~km} \times 5 \mathrm{~km}$ region.

information in Table IV and Fig. 7, for LUT-P and ANN-P methods, the RMSEs increase with absolute WVC errors for land surface and the uncertainty is generally smallest. While for water and snow and ice surfaces, the RMSEs increase with negative WVC errors whereas decrease slightly with positive WVC errors. With respect to the ANN method, the RMSEs change a little with negative WVC errors, while larger uncertainty occurs with positive WVC errors, for land and water surface. As for the snow and ice surface, the ANN method shows relatively large variation in RMSE with WVC errors.

In summary, it is reasonable to say that for land and water surfaces, the LUT-P and ANN-P methods are analogously 


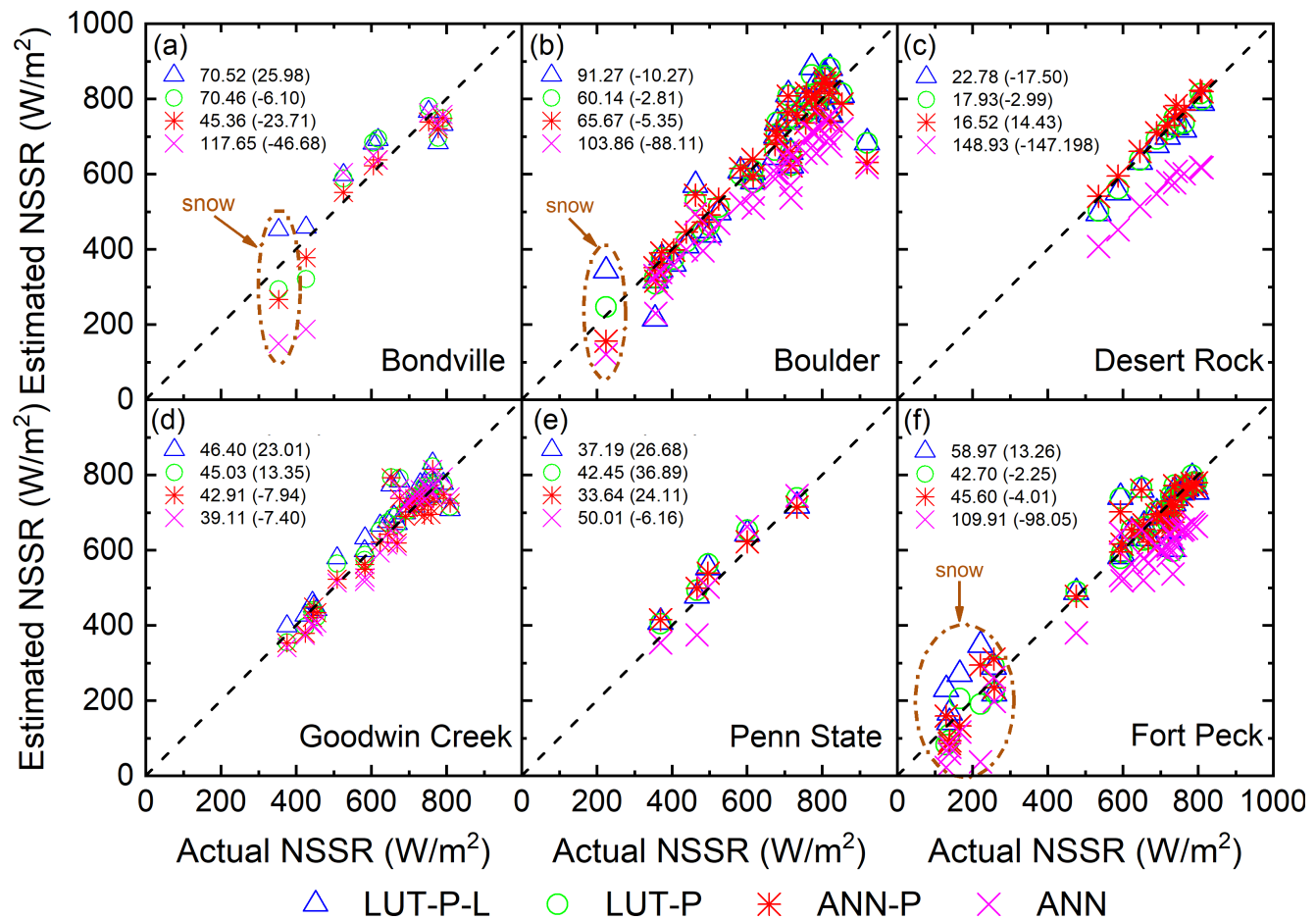

Fig. 9. Comparison between the measured NSSR and estimated NSSR with different methods (a)-(f) for six sites in SURFRAD network.

stable because of their similarly small RMSE changes. For snow and ice surface, the LUT-P method shows better stability in view of WVC errors. However, the ANN method shows much more uncertainty especially for snow and ice surface, in spite of the relatively better performance in model simulation. Overall, it is not beyond speculation that the proposed ANN-P method denotes the preference option for NSSR estimation under clear sky condition, for land and water surfaces. While in snow and ice cases, the ANN-P method may present greater uncertainty than LUT-P method considering WVC errors.

\section{VALIDATION}

\section{A. Spatial Heterogeneity of in Situ Measurement}

To examine the reliability of the in situ measurement, a relative bias (RB) indicator was constructed to quantify the spatial representativeness. The spatial heterogeneity of the seven SURFRAD sites was further quantified by relative standard deviation (RSD) within a $5 \mathrm{~km} \times 5 \mathrm{~km}$ neighbor around the ground station [48]. The RB and RSD are is expressed as follows:

$$
\begin{aligned}
\mathrm{RB} & =\frac{|\mathrm{NSSR}-\overline{\mathrm{NSSR}}|}{\overline{\mathrm{NSSR}}} \times 100 \% \\
\mathrm{RSD} & =\frac{\mathrm{NSSR}_{\mathrm{SD}}}{\overline{\mathrm{NSSR}}} \times 100 \%
\end{aligned}
$$

where NSSR is the ground measured NSSR, NSSR and NSSR $_{\text {SD }}$ are the mean NSSR and the standard deviation (SD) of NSSR within a $5 \mathrm{~km} \times 5 \mathrm{~km}$ neighbor around the ground station, respectively. It could be used to indicate the degree of approximation of the ground-based NSSR and satellite-based NSSR estimation. Based on the proposed ANN-P method, the NSSR in $5 \mathrm{~km} \times 5 \mathrm{~km}$ of each SURFRAD site could be estimated to calculate the RB at different months to indicate the seasonal variation. Finally, six stations with RSD under 5\% and a majority of RBs under $10 \%$ were selected as proper in situ measurement. As in Fig. 8, except for the spring situation at Bondville and Fort Peck, and the winter situation at Fort Peck, all other RBs are under $10 \%$, which indicate a well spatial representativeness and small spatial heterogeneity for the six stations.

\section{B. Validation With Satellite Data}

To validate the feasibility of using GF-5 to estimate NSSR, all the three aforementioned methods are validated with ground measurements. Additionally, the previous method that employed MODTRAN simulated samples without considering surface non-Lambertian effect (LUT-P-L) is also introduced to compare [49]. Most of the selected ground measurements are located in land surface with several snow days. The result is shown in Fig. 9(a)-(f) with the snow samples denoted specifically. Given the LUT-P method, a few sites exhibit better accuracy (lower RMSE and MBE) when compared with the previous LUT-P-L method while some exhibit paralleled or slightly lower accuracy. By comparing the RMSEs between the LUT-P-L and LUT-P methods at each station, the mean relative error caused by not considering the BRDF effect is around 20\%. It indicates the importance of considering the non-Lambertian effect in NSSR estimation. The RMSEs of ANN-P method range between 16 and $65 \mathrm{~W} / \mathrm{m}^{2}$, which correspond to acceptable accuracy when compared to previous studies. The relatively worse accuracy of ANN-P in Boulder and Fort Peck is mainly due to the underestimation in snow days. Generally, the RMSEs and biases of most sites suggest 


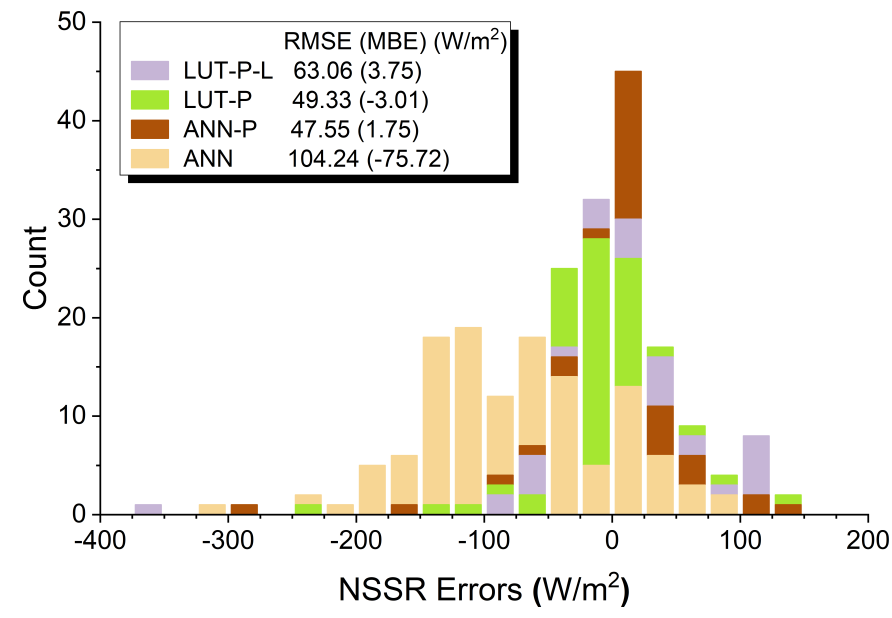

Fig. 10. Histogram of overall NSSR errors between the estimated NSSR $\left(\mathrm{NSSR}_{\mathrm{est}}\right)$ and measured NSSR (NSSR $\left.\mathrm{act}\right)\left(\mathrm{NSSR}_{\mathrm{est}}-\mathrm{NSSR}_{\mathrm{act}}\right)$ with different methods for the six ground measurement sites.

that the proposed ANN-P scheme exhibits relatively better or paralleled accuracy when compared with the aforementioned LUT-P-L and LUT-P methods. The RMSE and bias of ANN method are the highest among all these methods, which is in accordance with the previous sensitivity analysis of WVC that the uncertainty in ANN method is the largest. In summary, the ANN-P method exhibits optimal accuracy in validation, which is consistent with the result in simulation data set in Sections III-B and III-C.

Fig. 10 shows a histogram of the overall bias distribution. The proposed ANN-P scheme exhibits the largest frequency concentrated in center zero line, and this is followed by LUT-P and previous LUT-P-L schemes. With respect to the ANN method, a large bias is observed, and this could be due to the instability of the network trained by simulation data set, as explained in the WVC sensitivity analysis part in Section III-D. Overall, the mean RMSEs (MBEs) of all sites for the LUT-P-L, LUT-P, ANN-P, and ANN methods are, 63.06 (3.75), 49.33 (-3.01), 47.55 (1.75), and 104.24 $(-75.72) \mathrm{W} / \mathrm{m}^{2}$, respectively. The proposed ANN-P method exhibits a better performance in NSSR estimation under clear sky with GF-5 data.

It is difficult to retrieve precise auxiliary meteorological information at the SURFRAD ground site, and thus the satellite product MOD05_L2 with a spatial resolution of $1 \mathrm{~km}$ is employed to extract WVC, which could introduce some uncertainties in the NSSR estimation. This leads to relatively large bias like the underestimation in most sites for the ANN-P and ANN method. Specifically, the validation results further prove that the proposed ANN-P method that considers nonLambertian characteristics of a natural surface is feasible for GF-5 satellite data to estimate NSSR and improves accuracy.

\section{Discussion AND CONCLUSION}

In this study, an improved method for estimating NSSR from Chinese GF-5 data is developed. The method is implemented based on the MODTRAN 5.2 simulations. By considering the surface-atmosphere as a whole system and the non-Lambertian feature of natural underlying surface, the effect of surface directional reflectance is embodied via importing BRDF parameters from MODIS product to the MODTRAN procedure. A parameterization scheme is employed to estimate NSSR based on the linear relationship between surface absorption and TOA reflected flux. Given that most of the current satellites provide only narrowband data, the TOA broadband albedo is first retrieved based on a GA-BP network. The results indicate that the GA-BP network explains more than $99 \%$ of the TOA broadband albedo variations in the simulated data sets and that the RMSE is as low as 0.005 and reduced to over half when compared to the evaluation result with LUT parameters recalibrated with a new set of GF-5 simulation data set with surface directional reflectance. This indicates that the previous LUT-P method is not ideal in terms of estimating TOA broadband albedo for the non-Lambertian database. With respect to the NSSR estimation, the RMSEs of land, water, and snow and ice surfaces correspond to 17.07, 13.67 , and $29.99 \mathrm{~W} / \mathrm{m}^{2}$, respectively, for the previous LUT-P method. The corresponding values are 15.01, 10.04, and $20.39 \mathrm{~W} / \mathrm{m}^{2}$, respectively, for the improved ANN-P method. Their MBEs are within $0.9 \mathrm{~W} / \mathrm{m}^{2}$. In summary, the ANN-P method exhibits better accuracy than previous LUT-P scheme for each type of surface.

For further comparison, the ANN method is also employed to directly estimate NSSR by ignoring the calculation of TOA broadband albedo. Overall, the ANN method explains more than $99 \%$ of the NSSR variations in the simulated test data sets. The RMSEs of land, water, and snow and ice surface approximately correspond to $6.63,7.70$, and $2.70 \mathrm{~W} / \mathrm{m}^{2}$, respectively, in the testing data set. However, the sensitivity analysis result indicates that the proposed ANN-P method and previous LUT-P method is relatively stable. In summary, the proposed ANN-P method correspond to the preferred option for NSSR estimation under clear-sky condition.

In this study, we employed a novel perspective to take the atmosphere-Earth surface as a whole system. As the incident solar energy is absorbed by the system, NSSR could be readily retrieved by removing the atmospheric absorption from the total absorption through the atmosphere-Earth surface system. Due to the negligible absorption effect by aerosol on NSSR in the model, and the absence of cloud under the clearsky premise, only the variable absorptive gas molecule (e.g., WVC) was considered to indicate the atmospheric absorption in the methods.

By employing the Landsat 8 data as proxy of GF-5, the ground validation result reveals that the RMSEs of different sites range between 16 and $65 \mathrm{~W} / \mathrm{m}^{2}$, thereby indicating that the proposed ANN-P method that considers the nonLambertian characteristics of natural surface is feasible for GF-5 satellite data to estimate NSSR. Although some larger bias can occur in some cases, it is important to consider the effect of surface directional reflectance given that the result indicates that it plays an important role in the TOA broadband albedo estimation, which can further affect NSSR accuracy and should not be neglected in the NSSR estimation. It should be noted that the terrain effects should not be ignored in the high spatial resolution data set. In fact, we have considered the elevation effect implicitly by employing different WVCs, 
which is generally affected by the surface elevation, both in the MODTRAN simulation and the parameterization process. The effect of terrain geometries, such as the terrain slope, aspect, and shadow, are not considered at present. It is a meaningful research prospect and would be considered in future study.

This study includes a significant experiment to manifest the feasibility of NSSR study with Chinese GF-5. Furthermore, the 20-m high spatial resolution of MSI onboard GF-5 exhibits unprecedented advantages for potential applications including climate research, energy balance studies, and estimation of global evapotranspiration. It is necessary to incorporate the BRDF product to MODTRAN to simulate the reflectance of non-Lambertian surface and contribute to NSSR study in remote sensing realm. Furthermore, some available BRDF information should be potentially gathered to test the representativeness and accuracy of MODTRAN simulated surface directional reflectance in the future.

\section{REFERENCES}

[1] S. A. Christopher, "Satellite remote sensing methods for estimating clear sky shortwave top of atmosphere fluxes used for aerosol studies over the global oceans," Remote Sens. Environ., vol. 115, no. 12, pp. 3002-3006, Dec. 2011

[2] B.-H. Tang, Z.-L. Li, H. Wu, and R. Tang, "Estimation of daily net surface shortwave radiation from MODIS data," in Proc. IEEE Int. Geosci. Remote Sens. Symp. (IGARSS), Jul. 2015, pp. 25-28.

[3] J. D. Tarpley, "Estimating incident solar radiation at the surface from geostationary satellite data," J. Appl. Meteorol., vol. 18, no. 9, pp. 1172-1181, Sep. 1979

[4] Y. Zhang, W. B. Rossow, A. A. Lacis, V. Oinas, and M. I. Mishchenko, "Calculation of radiative fluxes from the surface to top of atmosphere based on ISCCP and other global data sets: Refinements of the radiative transfer model and the input data," J. Geophys. Res., vol. 109, no. D19, 2004, Art. no. D19105.

[5] N. G. Loeb et al., "Toward optimal closure of the Earth's top-ofatmosphere radiation budget," J. Climate, vol. 22, no. 3, pp. 748-766, Feb. 2009

[6] N. G. Loeb et al., "Observed changes in top-of-the-atmosphere radiation and upper-ocean heating consistent within uncertainty," Nature Geosci., vol. 5, no. 2, pp. 110-113, Feb. 2012.

[7] R. T. Pinker et al., "Surface radiation budgets in support of the GEWEX continental-scale international project (GCIP) and the GEWEX Americas prediction project (GAPP), including the North American land data assimilation system (NLDAS) project," J. Geophys. Res., Atmos., vol. 108 , no. D22, p. 8844 , Nov. 2003.

[8] A. Jia, S. Liang, B. Jiang, X. Zhang, and G. Wang, "Comprehensive assessment of global surface net radiation products and uncertainty analysis," J. Geophys. Res., Atmos., vol. 123, no. 4, pp. 1970-1989, Feb. 2018

[9] D. Sun, C. Ji, W. Sun, Y. Yang, and H. Wang, "Accuracy assessment of three remote sensing shortwave radiation products in the Arctic," Atmos. Res., vol. 212, pp. 296-308, Nov. 2018.

[10] V. Masson, J. L. Champeaux, F. Chauvin, C. Meriguet, and R. Lacaze, "A global database of land surface parameters at $1-\mathrm{km}$ resolution in meteorological and climate models," J. Clim., vol. 16, no. 9, pp. 1261-1282, 2003.

[11] A. Martilli, A. Clappier, and M. W. Rotach, "An urban surface exchange parameterisation for mesoscale models," Boundary-Layer Meteorol., vol. 104, no. 2, pp. 261-304, Aug. 2002.

[12] G. Bisht, V. Venturini, S. Islam, and L. Jiang, "Estimation of the net radiation using MODIS (moderate resolution imaging spectroradiometer) data for clear sky days," Remote Sens. Environ., vol. 97, no. 1, pp. 52-67, Jul. 2005.

[13] K. Masuda, H. G. Leighton, and Z. Li, "A new parameterization for the determination of solar flux absorbed at the surface from satellite measurements," J. Climate, vol. 8, no. 6, pp. 1615-1629, Jun. 1995.

[14] J. C. Klink and K. J. Dollhopf, "An evaluation of satellite-based insolation estimates for Ohio," J. Climate Appl. Meteorol., vol. 25, no. 11, pp. 1741-1751, Nov. 1986.

[15] R. Dubayah and S. Loechel, "Modeling topographic solar radiation using GOES data," J. Appl. Meteorol., vol. 36, no. 2, pp. 141-154, Feb. 1997.
[16] S. Liang, T. Zheng, R. Liu, H. Fang, S.-C. Tsay, and S. Running, "Estimation of incident photosynthetically active radiation from moderate resolution imaging spectrometer data," J. Geophys. Res., vol. 111, no. D15, 2006, Art. no. D15208.

[17] B. Tang, Z.-L. Li, and R. Zhang, "A direct method for estimating net surface shortwave radiation from MODIS data," Remote Sens. Environ., vol. 103, no. 1, pp. 115-126, 2006.

[18] H.-Y. Kim and S. Liang, "Development of a hybrid method for estimating land surface shortwave net radiation from MODIS data," Remote Sens. Environ., vol. 114, no. 11, pp. 2393-2402, Nov. 2010.

[19] X. Zhang, S. Liang, G. Zhou, H. Wu, and X. Zhao, "Generating global LAnd surface satellite incident shortwave radiation and photosynthetically active radiation products from multiple satellite data," Remote Sens. Environ., vol. 152, pp. 318-332, Sep. 2014.

[20] X. Zhang and L. Li, "Estimating net surface shortwave radiation from chinese geostationary meteorological satellite Feng Yun-2D (FY-2D) data under clear sky," Opt. Express, vol. 24, no. 6, p. A476, Mar. 2016.

[21] T. He, S. Liang, D. Wang, Q. Shi, and M. L. Goulden, "Estimation of high-resolution land surface net shortwave radiation from AVIRIS data: Algorithm development and preliminary results," Remote Sens. Environ., vol. 167 , pp. 20-30, Sep. 2015.

[22] J. Dozier and J. Frew, "Rapid calculation of terrain parameters for radiation modeling from digital elevation data," IEEE Trans. Geosci. Remote Sens., vol. 28, no. 5, pp. 963-969, Sep. 1990.

[23] X. Li, G. Cheng, X. Chen, and L. Lu, "Modification of solar radiation model over rugged terrain," Chin. Sci. Bull., vol. 44, no. 15, pp. 1345-1349, Aug. 1999.

[24] T. Wang, G. Yan, X. Mu, Z. Jiao, L. Chen, and Q. Chu, "Toward operational shortwave radiation modeling and retrieval over rugged terrain," Remote Sens. Environ., vol. 205, pp. 419-433, Feb. 2018.

[25] T. Wang, G. Yan, X. Mu, and L. Chen, "Clear sky net surface radiative fluxes over rugged terrain from satellite measurements," in Proc. IEEE Int. Geosci. Remote Sens. Symp., Jul. 2011, pp. 4265-4268.

[26] T. Wang et al., "Topographic correction of retrieved surface shortwave radiative fluxes from space under clear-sky conditions," in Proc. IEEE Geosci. Remote Sens. Symp., Jul. 2014, pp. 1813-1816.

[27] Y. Zhang, X. Li, and Y. Bai, "An integrated approach to estimate shortwave solar radiation on clear-sky days in rugged terrain using MODIS atmospheric products," Sol. Energy, vol. 113, pp. 347-357, Mar. 2015.

[28] G. Yan, T. Wang, Z. Jiao, X. Mu, J. Zhao, and L. Chen, "Topographic radiation modeling and spatial scaling of clear-sky land surface longwave radiation over rugged terrain," Remote Sens. Environ., vol. 172, pp. 15-27, Jan. 2016.

[29] D. Wang and S. Liang, "Estimating high-resolution top of atmosphere albedo from moderate resolution imaging spectroradiometer data," Remote Sens. Environ., vol. 178, pp. 93-103, Jun. 2016.

[30] Z. Li, H. G. Leighton, K. Masuda, and T. Takashima, "Estimation of SW flux absorbed at the surface from TOA reflected flux," J. Climate, vol. 6, no. 2, pp. 317-330, Feb. 1993.

[31] S.-H. Lee, B.-Y. Kim, K.-T. Lee, I.-S. Zo, H.-S. Jung, and S.-H. Rim, "Retrieval of reflected shortwave radiation at the top of the atmosphere using Himawari-8/AHI data," Remote Sens., vol. 10, no. 2, p. 213, Feb. 2018.

[32] S. Dewitte and N. Clerbaux, "Measurement of the Earth radiation budget at the top of the atmosphere-A review," Remote Sens., vol. 9, no. 11, p. 1143, Nov. 2017

[33] X. Niu and R. T. Pinker, "Revisiting satellite radiative flux computations at the top of the atmosphere," Int. J. Remote Sens., vol. 33, no. 5, pp. 1383-1399, Mar. 2012.

[34] N. G. Loeb, P. O. Hinton, and R. N. Green, "Top-of-atmosphere albedo estimation from angular distribution models: A comparison between two approaches," J. Geophys. Res., Atmos., vol. 104, no. D24, pp. 31255-31260, Dec. 1999 .

[35] N. G. Loeb, S. Kato, K. Loukachine, N. Manalo-Smith, and D. R. Doelling, "Angular distribution models for top-of-atmosphere radiative flux estimation from the clouds and the Earth's radiant energy system instrument on the TerraSatellite-Part II: Validation," J. Atmos Ocean Technol., vol. 24, no. 4, pp. 564-584, 2007.

[36] W. Su, J. Corbett, Z. Eitzen, and L. Liang, "Next-generation angular distribution models for top-of-atmosphere radiative flux calculation from CERES instruments: Methodology," Atmos. Meas. Techn., vol. 8, no. 2, pp. 611-632, Feb. 2015.

[37] T. Russkova and T. Zhuravleva, "Top-of-atmosphere reflectance over homogeneous Lambertian and non-Lambertian surfaces," Appl. Opt., vol. 57, no. 22, pp. 6345-6357, Aug. 2018. 
[38] A. Mousivand, W. Verhoef, M. Menenti, and B. Gorte, "Modeling top of atmosphere radiance over heterogeneous non-Lambertian rugged terrain," Remote Sens., vol. 7, no. 6, pp. 8019-8044, Jun. 2015.

[39] P. Gupta, J. Joiner, A. Vasilkov, and P. K. Bhartia, "Top-of-theatmosphere shortwave flux estimation from satellite observations: An empirical neural network approach applied with data from the Atrain constellation," Atmos. Meas. Techn., vol. 9, no. 7, pp. 2813-2826, Jul. 2016.

[40] D. Wang, S. Liang, and T. He, "Mapping high-resolution surface shortwave net radiation from Landsat data," IEEE Geosci. Remote Sens. Lett., vol. 11, no. 2, pp. 459-463, Feb. 2014.

[41] B.-H. Tang, "Nonlinear split-window algorithms for estimating land and sea surface temperatures from simulated Chinese Gaofen-5 satellite data," IEEE Trans. Geosci. Remote Sens., vol. 56, no. 11, pp. 6280-6289, Nov. 2018.

[42] H. Ren, X. Ye, R. Liu, J. Dong, and Q. Qin, "Improving land surface temperature and emissivity retrieval from the Chinese Gaofen-5 satellite using a hybrid algorithm," IEEE Trans. Geosci. Remote Sens., vol. 56, no. 2, pp. 1080-1090, Feb. 2018.

[43] Y. Chen, S.-B. Duan, J. Labed, and Z.-L. Li, "Development of a split-window algorithm for estimating sea surface temperature from the Chinese Gaofen-5 data," Int. J. Remote Sens., vol. 40, nos. 5-6, pp. 1621-1639, Mar. 2019.

[44] C. B. Schaaf et al., "First operational BRDF, albedo nadir reflectance products from MODIS," Remote Sens. Environ., vol. 83, nos. 1-2, pp. 135-148, Nov. 2002.

[45] J.-L. Roujean, M. Leroy, and P.-Y. Deschamps, "A bidirectional reflectance model of the Earth's surface for the correction of remote sensing data," J. Geophys. Res., Atmos., vol. 97, no. D18, pp. 20455-20468, 1992.

[46] M. C. Hansen, R. S. Defries, J. R. G. Townshend, and R. Sohlberg, "Global land cover classification at $1 \mathrm{~km}$ spatial resolution using a classification tree approach," Int. J. Remote Sens., vol. 21, nos. 6-7, pp. 1331-1364, Jan. 2000.

[47] K. Suzuki, Artificial Neural Networks: Methodological Advances and Biomedical Applications. Norderstedt, Germany: BoD-Books on Demand, 2011.

[48] W. Yu, M. Ma, Z. Li, J. Tan, and A. Wu, "New scheme for validating remote-sensing land surface temperature products with station observations," Remote Sens., vol. 9, no. 12, p. 1210, Nov. 2017.

[49] M. Si, B.-H. Tang, R. Tang, H. Wu, Z.-L. Li, and G. Shang, "Estimation of net surface shortwave radiation from simulated Chinese Gaofen-5 satellite data," in Proc. IEEE Int. Geosci. Remote Sens. Symp. IGARSS, Jul. 2019, pp. 1978-1981.

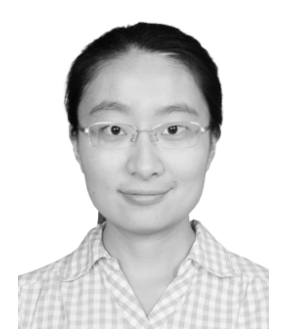

Menglin Si (Student Member, IEEE) received the B.S. degree in geographical information system from Wuhan University, Wuhan, China, in 2014, and the M.S. degree in urban and regional planning from Peking University, Beijing, China, in 2017. She is currently pursuing the Ph.D. degree with the Institute of Geographic Sciences and Natural Resources Research, Chinese Academy of Sciences, Beijing, and with the College of Resources and Environment, University of Chinese Academy of Sciences, Beijing.

She is also a Joint Student with the ICube Laboratory, CNRS-University of Strasbourg, Illkirch, France.

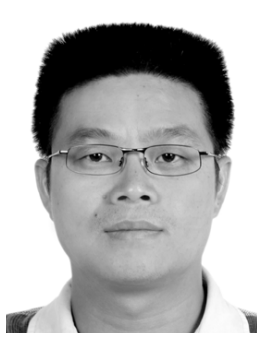

Bo-Hui Tang (Senior Member, IEEE) received the B.S. degree in cartography and geographical information system from Wuhan University, Wuhan, China, in 1999, the M.S. degree in cartography and geographical information system from China Remote Sensing Satellite Ground Station, Chinese Academy of Sciences, Beijing, China, in 2004, and the Ph.D. degree in cartography and geographical information system from the Institute of Geographic Sciences and Natural Resources Research, Chinese Academy of Sciences, in 2007.

$\mathrm{He}$ is a Research Fellow with the Institute of Geographic Sciences and Natural Resources Research. His research interests include the retrieval and validation of surface net radiation and surface temperature.
Zhao-Liang Li (Senior Member, IEEE) received the Ph.D. degree in geophysics and remote sensing from the University of Strasbourg, Strasbourg, France, in 1990.

Since 1992, he has been a Research Scientist with CNRS, Illkirch, France. $\mathrm{He}$ joined the Institute of Agricultural Resources and Regional Planning, Beijing, China, in 2013. He is also a Research Fellow with the Institute of Geographic Sciences and Natural Resources Research, Beijing. He has participated in many national and international projects, such as NASA-funded MODIS, EC-funded program EAGLE, and ESA funded programs SPECTRA. He has authored more than 150 articles in international refereed journals. His research interests include thermal infrared radiometry, parameterization of land surface processes at large scale, and the assimilation of satellite data to land surface models.

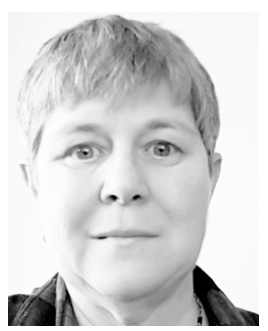

Francoise Nerry received the Ph.D. degree from the University of Strasbourg, Strasbourg, France, in 1988.

She held a Post-Doctoral Fellowship at JPL, Pasadena, CA, USA, for two years. She joined the Image Sciences, Computer Sciences and Remote Sensing Laboratory (LSIIT), LSIIT changed to ICube in 2013, Illkirch, France, as a Permanent CNRS Researcher. She is responsible for the Earth observation theme of the TRIO/ICube Team involving 40 persons, including 20 permanents. She has been involved in numerous national and international programs. Her research interests include thermal infrared radiometry and methodology of physical analysis of remote sensing data.

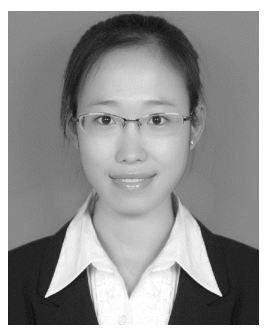

Xia Zhang was born in Shijiazhuang, Hebei, China, in 1985. She received the B.S. degree in geographic information system from Changchun Normal University, Changchun, China, in 2008, and the M.S. and $\mathrm{Ph} . \mathrm{D}$. degrees in cartography and geographic information system from Northeast Normal University, Changchun, in 2010 and 2014, respectively.

Since 2014, she has been a Lecturer with the College of Land Resources and Urban and Rural Planning, Hebei GEO University, Shijiazhuang. Her research interests include the thermal infrared polarization remote sensing, multiangle and hyperspectral remote sensing, and quantitative remote sensing.

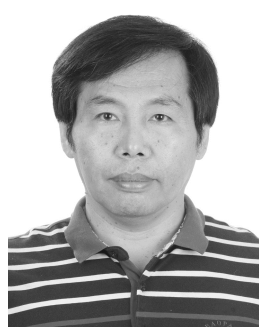

Guofei Shang was born in Tangshan, Hebei, China, in 1964. He received the B.E. degree in aerial photogrammetry and remote sensing from Wuhan University, Wuhan, China, in 1985, and the M.E. and $\mathrm{Ph} . \mathrm{D}$. degrees in land resources management from the Renmin University of China, Beijing, China, in 1992 and 2002, respectively.

Since 1997, he has been a Professor and the Dean of the College of Land Resources and Urban and Rural Planning, Hebei GEO University, Shijiazhuang, China. His research interests include the aerial photogrammetry and remote sensing, quantitative remote sensing, and natural resources management. 